\title{
Escape Mutant
}

National Cancer Institute

\section{Source}

National Cancer Institute. Escape Mutant. NCI Thesaurus. Code C14375.

HIV mutants which have overcome drug inhibition. 